GRUNBERG (Bernard), L'Inquisition apostolique au Mexique. Histoire d'une institution et de son impact dans une société coloniale (1521-1571)

Paris, L'Harmattan, 1998, 237 p. (bibliogr., tablx, graphiques, illustr., cartes) (coll. « Recherches et Documents Amériques latines »)

\title{
Carmen Bernand
}

\section{OpenEdition}

\section{Journals}

Édition électronique

URL : http://journals.openedition.org/assr/20557

DOI : 10.4000/assr.20557

ISSN : $1777-5825$

Éditeur

Éditions de l'EHESS

Édition imprimée

Date de publication : 1 juillet 2000

Pagination : $79-80$

ISBN : 2-222-96691-4

ISSN : 0335-5985

Référence électronique

Carmen Bernand, « GRUNBERG (Bernard), L'Inquisition apostolique au Mexique. Histoire d'une institution et de son impact dans une société coloniale (1521-1571)», Archives de sciences sociales des religions [En ligne], 110 | avril-juin 2000, document 110-23, mis en ligne le 19 août 2009, consulté le 21 septembre 2020. URL : http://journals.openedition.org/assr/20557 ; DOI : https://doi.org/10.4000/assr.20557

Ce document a été généré automatiquement le 21 septembre 2020.

(C) Archives de sciences sociales des religions 


\section{GRUNBERG (Bernard), L'Inquisition apostolique au Mexique. Histoire d'une institution et de son impact dans une société coloniale (1521-1571)}

Paris, L'Harmattan, 1998, 237 p. (bibliogr., tablx, graphiques, illustr., cartes) (coll. « Recherches et Documents Amériques latines »)

\section{Carmen Bernand}

\section{RÉFÉRENCE}

GRUNBERG (Bernard), L'Inquisition apostolique au Mexique. Histoire d'une institution et de son impact dans une société coloniale (1521-1571), Paris, L'Harmattan, 1998, 237 p. (bibliogr., tablx, graphiques, illustr., cartes) (coll. « Recherches et Documents Amériques latines »)

1 Avant l'instauration dans le Nouveau Monde de tribunaux formels pour réprimer les hérésies, ce furent les ordres missionnaires (franciscains, puis dominicains) qui se chargèrent des jugements ordinaires ecclésiastiques. En 1536, le franciscain Juan de Zumârraga, évêque de la Nouvelle Espagne, établit le tribunal de l'Inquisition apostolique épiscopale, qui accordait aux évêques la gestion des affaires liées aux délits contraires à la religion. Ce n'est qu'en 1571 que le Tribunal du Saint-Office fut implanté au Mexique et au Pérou. Le livre de B.G. porte sur cette première phase de l'Inquisition, qui est aussi la moins bien connue. Elle nous intéresse pour plusieurs raisons, l'une d'elles étant la place occupée dans les procès par les idolâtries des Indiens : le premier procès connu fut celui de Marcos, un Indien d'Acolhuacan, en 1522. À partir de 1571, les populations autochtones américaines ne relèvent plus de la juridiction du Saint-Office, qui juge les délits des Espagnols, des Noirs, des métis, des étrangers hérétiques et des juifs. 
2 B.G. étudie donc cette première phase de l'Inquisition et fournit un certain nombre d'exemples concernant la répression des délits. Les religieux s'attaquèrent d'abord à canaliser l'indiscipline surgie à l'époque de la conquête. Il est significatif que le blasphème ait été la principale cible de leur action. Les premiers procès contre les judaïsants eurent lieu dès 1528 . Sur ces questions il n'y a pas de documents de première main et l'auteur se fonde sur une enquête effectuée en 1574, et qui portait sur les sanbenitos de la période antérieure à l'implantation du Saint-Office. Parmi les exemples donnés, on retrouve celui de Hernando Alonso, survivant de la Noche Triste, encomendero à Actopan et personnage important (et non pas conquistador modeste, comme il est dit à la page 112). Ce cas, ainsi que d'autres comme Diego de Ocana, sont d'ailleurs connus des spécialistes du Mexique, puisqu'ils ont été analysés par Richard Greenleaf dans un ouvrage désormais classique, où il montrait que les procès visaient principalement les hommes de l'entourage de Hernan Cortés (cf. Richard Greenleaf, The Mexican Inquisition in the Sixteenth Century, Albuquerque, University of Mexico Press, 1969).

3 Juan de Zumârraga fut le promoteur de la première grande campagne contre les idolâtries, marquée par le procès de don Carlos Ometochtzin, cacique de Tezcoco en 1531. Après enquête réalisée par le franciscain fray Andrés de Olmos à Matatlan, il s'avéra que cet homme de haut rang pratiquait des idolâtries. Il fut condamné au fouet et à la tonsure. La lutte contre les idolâtries réprima surtout le concubinage, la polygamie et la bigamie. Mais contrairement à ce qui se passait en Espagne à la même époque à l'égard des Juifs et des Morisques, au Mexique, l'attitude de l'Église envers les Indiens fut moins sévère.

4 La lutte contre l'hérésie luthérienne, dans le cadre de la Contre-réforme, constitue une activité majeure de l'Inquisition apostolique. Là encore l'A. n'apporte pas de cas vraiment nouveaux par rapport aux travaux de R. Greenleaf, mais fournit une chronologie utile des incursions sur les côtes mexicaines des corsaires français et anglais. Un autre problème auquel se heurtèrent les Inquisiteurs fut celui de la diffusion de livres interdits, notamment ceux qui traitaient des questions indiennes imprimés dans le Nouveau Monde sans licence. Le livre de B.G. s'achève sur une proposition de comparatisme avec le fonctionnement de l'Inquisition apostolique au Pérou, sur laquelle on ne connaît que l'apport de José Toribio Médina. Nous espérons que l'exploitation de sources nouvelles lui permettra de relever ce défi. 